\title{
Design Methodology and Analysis of Double Cavity Metal-Plastic-Insert Injection Molding Die for Push Board Pin
}

\author{
Neeraj Kumar Jha ${ }^{1}$ and P. V. Ramana ${ }^{2}$ \\ ${ }^{1}$ Assoc. Professor, CVR College of Engineering/ Mechanical Department, Hyderabad, India \\ Email: neerajjha.me@gmail.com \\ ${ }^{2}$ Assoc. Professor, CVR College of Engineering/ Mechanical Department, Hyderabad, India \\ Email: pvramana1964@gmail.com
}

\begin{abstract}
Properties like high strength, light weight and moldability grants vital use of plastics in manufacturing industries, especially for mass production of products. Injection molding dies are often called plastic molds, are one of the tools for processing plastics to desired shape. It is very easy to understand and perform processes like injection molding to obtain plastic products. But dies developed by correct design steps only can produce defect free products. Insert injection molding is a type of injection molding process in which metal inserts are incorporated in process of injection molding and later they becomes part of product. The purpose of this paper is to discuss the methodology involved with design and development of injection molding die for Push Board Pin. Software used for modeling of parts is UG Nx 8.0 and that for the simulation of process parameters is Autodesk Moldflow Adviser.
\end{abstract}

Index Terms: Moldability, Mass Production, Tool, Plastic Mold, Die, Insert Injection Molding, UG Nx 8.0, Autodesk Moldflow Adviser

\section{INTRODUCTION}

Injection molding is essentially the same process as hot chamber die casting. Similar to the process of extrusion, the barrel (cylinder) is heated to promote melting. The pallets or granules are fed into the heated cylinder, and the melt is forced into a split-die chamber, either by hydraulic plunger or by the rotating screw system of an extruder [1]. This split-die is often termed as plastic mold and is obtained by following correct design steps. After the die or mold cavity is filled, it is allowed to cool or cure, then the molds are opened and the solidified part is ejected. The molds are then closed and the process is repeated. Because the material is injected into the mold in molten state, complex shape with good dimensional accuracy can be obtained.

Metallic components such as screws, pins and strips can be placed in the mold cavity and becomes an integral part of the injection molding product, such type of injection molding is referred as Insert Injection Molding. The most common examples of such combinations are electrical components [1]. The process is employed preferably to take advantage of different property of different parts in a single product. For example, in case of an insert injection molded electrical component there can be utilization of conductivity of copper insert and insulation as well as appearance of plastic part molded over it. In another example it could be strength and durability of metallic insert with noncorrosive artistic layer of plastics molded over it.
Push board pins are another example for insert injection molding process. They are also referred as push pin and drawing board pin. These comprise two parts viz. metallic body and plastic head. Its body is a pointed metallic pin and head is usually molded with plastic to achieve various decorative shape and sizes. By holding its plastic head, the pin is inserted against a surface. Usage of such pins is preferably for holding paper against a board or pointing any location on a map.

For obtaining such pins, die (mold) cavity is made according to expected shape and size of head. This cavity usually consists of provision or space to accommodate pre formed pin. First pin is placed in die cavity as insert. Then the die is closed and molten plastic is injected with pressure to occupy shape of head. During solidification, plastic sticks around the projected part of pin in the cavity. The die is then opened and the component is taken out.

Though the process appears simple, it is difficult to obtain a quality product without following the correct methodology of injection mold design. The correct methodology for a plastic mold design is briefly shown in Figure 1 [2].

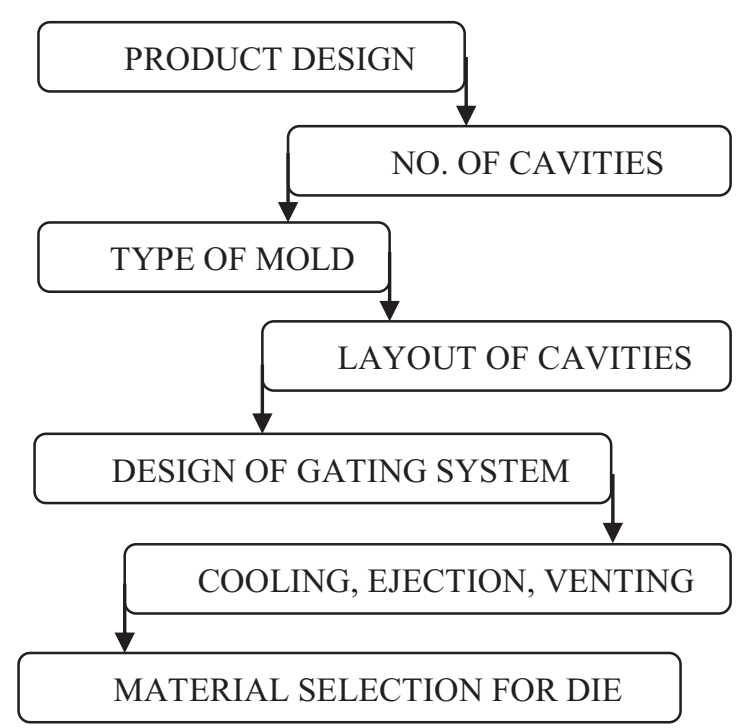

Figure 1. Design Methodology for Plastic Mold 


\section{Product Design}

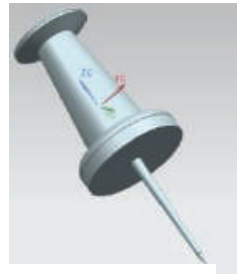

EXISTING

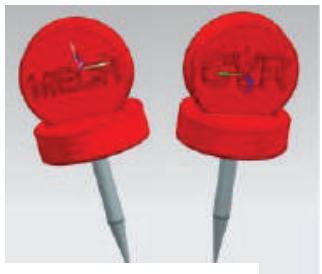

DESIGNED
Figure 2. View of Product, Finalized for Further Analysis

In the phase of product design a product is observed for its manufacturability by a particular process of manufacturing. The finalized product for this research work is different from the existing one, as shown in Figure 2.

TABLE I.

PRODUCT SPECIFICATION

\begin{tabular}{|l|l|}
\hline Part Name & Push board pin \\
\hline Material & Polypropylene head, Steel insert \\
\hline Part Volume & $465 \mathrm{~mm}^{3}$ (excluding insert) \\
\hline Surface Area & $480 \mathrm{~mm}^{2}$ (excluding insert) \\
\hline Mass & $0.5 \mathrm{gm} \mathrm{(excluding} \mathrm{insert)}$ \\
\hline
\end{tabular}

Table I represents few specifications related to the designed product. The designed product for this research work has to serve the same purpose as the existing one. But its design is improved for advantages like increase in grip area as well as in area for contact with paper. Simple design and sufficient space for personalized engraving are other advantages. Simple design leads to ease in design and manufacturing of mold. Engraving on flat face increases complexity of design but the same acts as means of extra material deposition to overcome shrinkages. Therefore, the achieved design of product is unique and profitable technically.

Material selection for molding process is another important aspect to decide in design phase. Polypropylene is selected for this purpose due to its own advantages. Few of the important characteristics of polypropylene (PP) are enlisted in Table II.

TABLE II.

MATERIAL SPECIFICATION

POLYPROPYLENE (PP)

\begin{tabular}{|l|l|}
\hline Density & $946 \mathrm{~kg} / \mathrm{m}^{3}$ \\
\hline Melting Point & $160^{\circ} \mathrm{C}$ \\
\hline Formula & $\left(\mathrm{C}_{3} \mathrm{H}_{6}\right)_{\mathrm{n}}$ \\
\hline Type & Thermoplastic \\
\hline Melting Point & $171{ }^{\circ} \mathrm{C}$ \\
\hline Flexural Strength & $40 \mathrm{~N} / \mathrm{mm}^{2}$ \\
\hline Shrinkage & $1-2.5 \% \mathrm{~mm} / \mathrm{mm}$ \\
\hline Tensile Strength & $32 \mathrm{~N} / \mathrm{mm}^{2}$ \\
\hline Injection Temperature & $32-36{ }^{\circ} \mathrm{C}$ \\
\hline Heat Deflection Temperature & $100{ }^{\circ} \mathrm{C}$ \\
\hline Specific Gravity & 0.91 \\
\hline
\end{tabular}

Figure 3 shows dimensions of various profiles for head of finalized product, on which design of mold will be based.
The design is based on prototyped and observed dimension. It is modeled and drafted using UG Nx 8.0
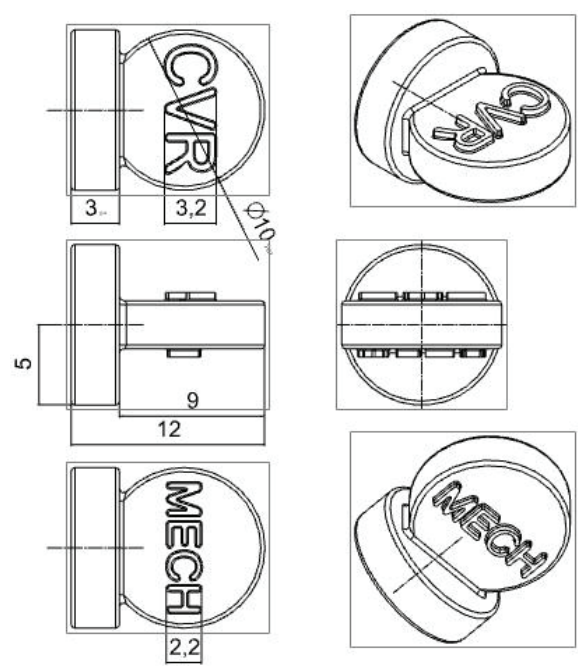

Figure 3. Drafting of Part (All dimensions are in $\mathrm{mm}$ )

\section{Design Calculations and Tool Design}

Once the part design is finalized, one can proceed with design procedure of tool.

\section{A. Number of Cavity}

Decision of number of cavity in the mold is first and foremost step of this procedure. The decision gets direct influence from number of component to be produced according to the order as well as from specifications or capacity of molding machine available with the manufacturer. Less number of cavity in the mold refers to longer lead time and the same time more number of cavity can be responsible for defective products. Table III represents common specification of an injection molding machine.

TABLE III.

MACHINE SPECIFICATION

(TEXPLASST 1HD, PT LAB, CVRCE)

\begin{tabular}{|l|l|}
\hline Shot Capacity & $2-45 \mathrm{gms} / \mathrm{shot}$ \\
\hline Plunger Diameter & $25 \mathrm{~mm}$ \\
\hline Stroke Lenght & $450 \mathrm{~mm}$ \\
\hline Clamping Capacity & $6.0 \mathrm{Tons}$ \\
\hline Injection Pressure & $80 \mathrm{~kg} / \mathrm{cm}^{2}$ \\
\hline Heating Capacity & $1.5 \mathrm{kw}$ \\
\hline Total Installed Power & $3.7 \mathrm{kw}$ \\
\hline Total Shut Height & $100-450 \mathrm{~mm}$ \\
\hline
\end{tabular}

Therefore, the reasonable number of cavity must be calculated for a mold. Out of various methods, Number of cavity based on shot capacity can be obtained as shown in equation 1 [2],

$$
N s=\frac{0.85 M s-R w}{C w}
$$


Where,

Ns $=$ No. of cavity based on shot capacity

(Based on $85 \%$ of rated shot capacity)

$\mathrm{Ms}=$ Rated shot capacity of machine (gm/shot)

$\mathrm{Rw}=$ Weight of all sprues and runners $(\mathrm{gm})$

$\mathrm{Cw}=$ Component weight per cavity $(\mathrm{gm})$

$$
N s=\frac{0.85 X 5-2.5}{0.5}=3.5
$$

Therefore, the possible number of cavity is 3.5 , but for simplicity of mold design, two cavities in mold can be accepted. Two cavities ensure easy balancing of mold as well as mold manufacturing also becomes simple to much extent.

\section{B. Type of Mold}

By seeing draft analysis of part as in Figure 4, it appears clearly that for the component two plate molds with symmetric parting line is the most feasible solution. Figure 5 indicates parting plane, along which splitting of cope half and drag half can be done for the design of two plate mold.

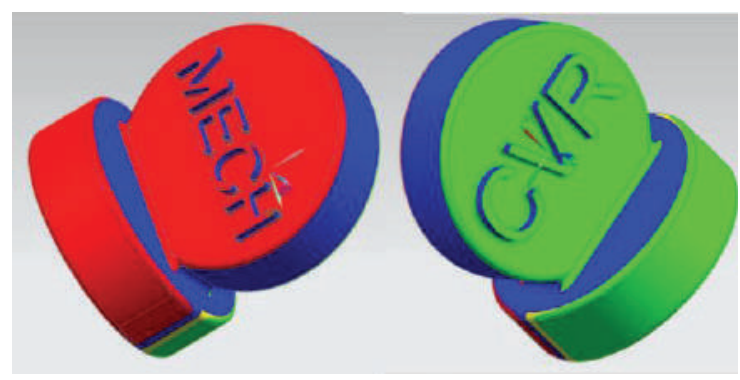

Figure 4. Draft analysis (Red: Cope half, Green: Drag half)

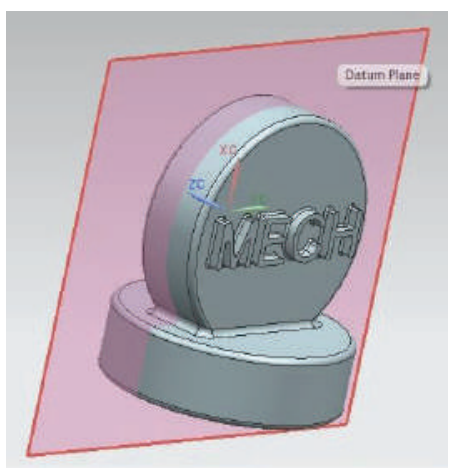

Figure 5. Parting Plane

\section{Layout of Cavities}

Based on above facts, layout of cavities can be represented as shown in Figure 6. But design of flow path plays a vital role here. Flow path is the channel made in mold, through which molten material enters into the mold cavity.

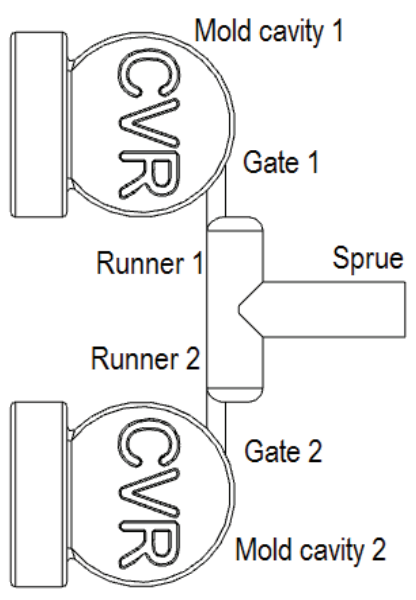

Figure 6. Layout of Two Cavity Symmetrical Arrangement

Sprue is the first element of flow path and its diameter used to be usually 0.5 to $1 \mathrm{~mm}$ bigger than machine nozzle diameter. Bigger sprue dimension may contribute to higher shot volume. Therefore, the length of sprue must be kept as less as possible. The runner is second part of flow path that connects sprue to the gate. Its diameter can be calculated as shown in equation 2 [3],

$$
D=\sqrt{W} \times \sqrt[4]{L} / 3.7
$$

Where,

$$
\begin{aligned}
& \mathrm{D}=\text { Runner Diameter }(\mathrm{mm}) \\
& \mathrm{W}=\text { Weight of the component }(\mathrm{gm}) \\
& \mathrm{L}=\text { Runner length }(\mathrm{mm})
\end{aligned}
$$

$$
\begin{aligned}
D & =\sqrt{1} X \sqrt[4]{40} / 3.7 \\
& =1.45 \mathrm{~mm}
\end{aligned}
$$

This small value has arrived due to less weight of component as well as due to less number of cavities. The runner should not be below $2 \mathrm{~mm}$ or above $12 \mathrm{~mm}$ diameter [2]. Therefore, $3 \mathrm{~mm}$ runner diameter is considered for flow path design.

The gate is of smallest cross section in the flow path. Through gate molten material enters into the mold cavity. By considering cylindrical cross section of sprue and runner, the gate diameter can be taken as one third of the runner diameter i.e. $1 \mathrm{~mm}$.

\section{Shot Volume}

Shot volume is volume of material sufficient enough to fill all the cavities of the die for one shot [3].

$$
S v=V s+V r+V g+V c
$$

Where,

$$
\begin{aligned}
& \mathrm{Sv}=\text { shot volume }\left(\mathrm{mm}^{3}\right) \\
& \mathrm{Vs}=\text { volume of sprue }\left(\mathrm{mm}^{3}\right) \\
& \mathrm{Vr}=\text { volume of runner }\left(\mathrm{mm}^{3}\right) \\
& \mathrm{Vg}=\text { volume of gate }\left(\mathrm{mm}^{3}\right) \\
& \mathrm{Vc}=\text { volume of mold cavity }\left(\mathrm{mm}^{3}\right)
\end{aligned}
$$

All these values can be easily obtained with help of modeled parts.

$$
\begin{aligned}
S v & =41+62+24+930 \\
& =1057 \mathrm{~mm}^{3}
\end{aligned}
$$




\section{Clamping capacity Calculation}

Clamping capacity allows the mold plates to stick with each other at the time of injection. It actually overcomes the injection pressure. It can be calculated by equation 4 [3].

$$
C f=P P A X \frac{1}{3}(I P)
$$

Where,

$$
\begin{aligned}
& \mathrm{C} f=\text { Clamping Capacity }(\mathrm{kg}) \\
& \mathrm{PPA}=\text { Plan Projected Area Of Mold }\left(\mathrm{cm}^{2}\right) \\
& \mathrm{IP}=\text { Injection Pressure }\left(\mathrm{kg} / \mathrm{cm}^{2}\right)
\end{aligned}
$$

$$
C f=2.4 X \frac{1}{3}(80)=64 \mathrm{~kg}
$$

\section{Process Simulation}

Autodesk Moldflow Adviser is a simulation tool. It provides details regarding feasibility of designed mold for producing a quality component. By this way we get correct manufacturability guidance for a mold. Using the same software design aspects like cooling or venting requirements can be estimated in our die, as for smaller cavities such entities are difficult to estimate numerically.

\section{A. Gating Stability}

When checked about proper gating position, the result obtained as shown in Figure 7 indicates that except engravings any other position is suitable for material flow into the cavity i.e. to be assumed as gate position.

This actually approves our approach of taking parting line along periphery of component. Therefore, the gate is arranged along parting line for ease of manufacturing of mold.

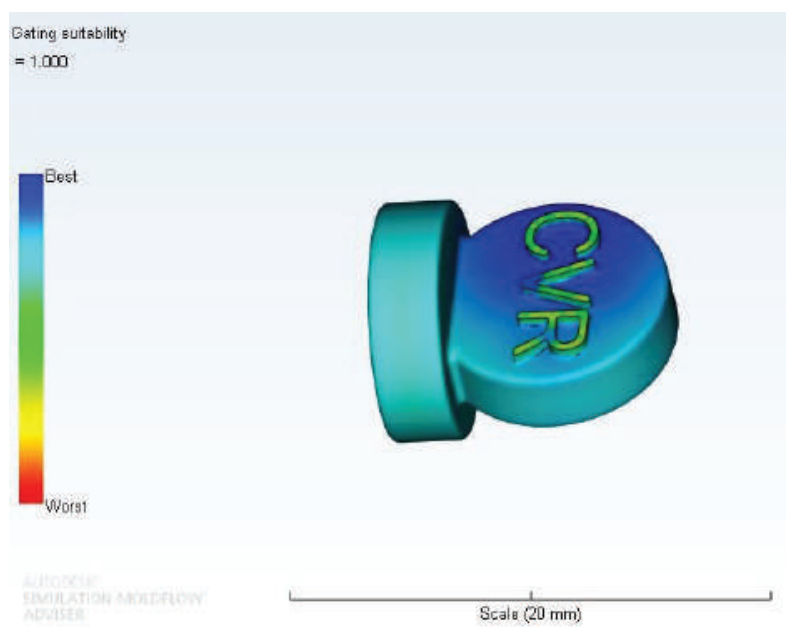

Figure 7. Gating Position All Over the Surface except Engravings

\section{B. Gating Stability}

Some values were taken from standards rather than accepting values obtained by imperial relations. Part and flow path were modeled according to these values. Then the model including flow path was taken for analysis. After analysis the result was displayed in Figure 8. It indicates high possibility of filling of mold cavity. This clearly indicates that the values considered from standards were acceptable.

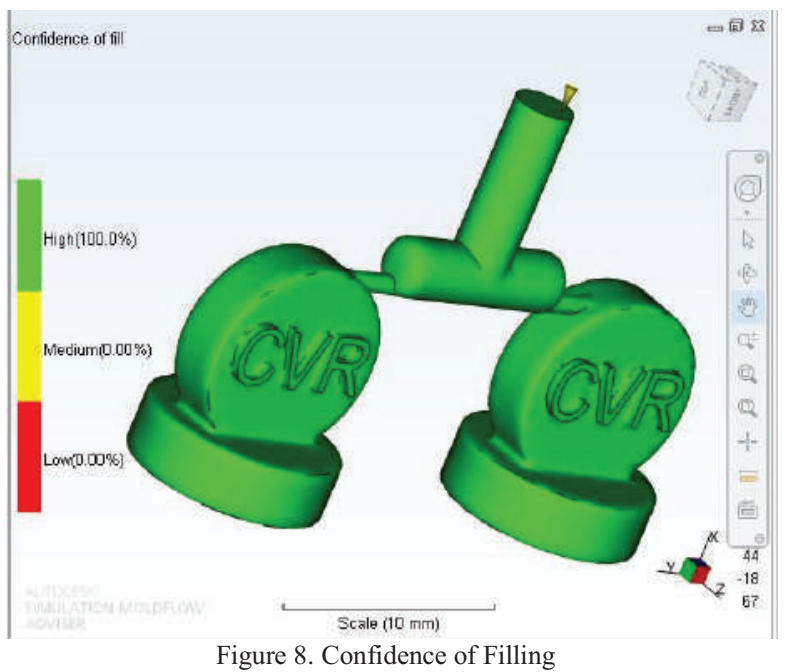

\section{Fill Time}

Fill time of mold directly affects cycle time of the process. Higher fill time indicates slow flow of material, which can cause cold shut and improper filling of cavity. Actually a slow moving flow front may lose its temperature to become solid, thereby hindering further flow of material. As indicated in Figure 9, result of fill time is also acceptable. Uniformity of filling of both the cavities can also be observed.

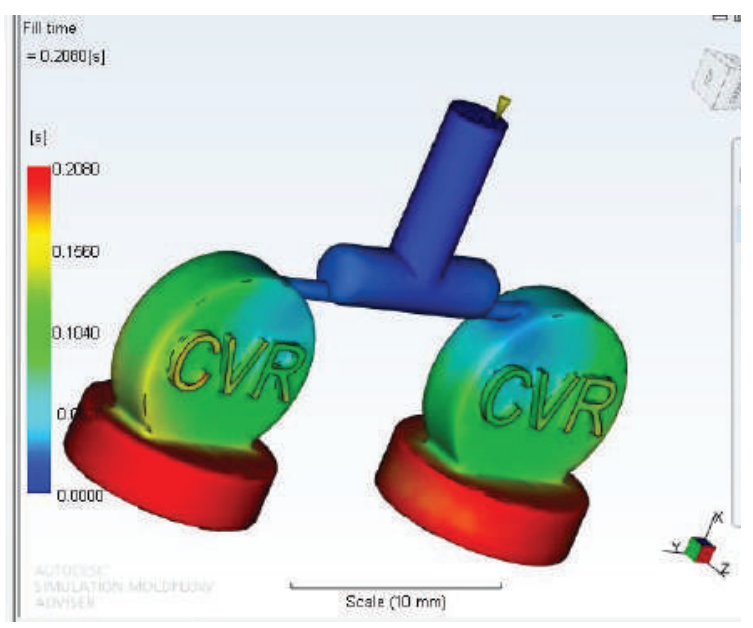

Figure 9. Low Fill Time Contributes to Optimum Cycle Time

\section{Temperature Variance}

Figure 10 shows analysis result of temperature variance. It is observable that the maximum temperature is at junction of both the circular profiles, which is acceptable. In actual practice this place will be accompanied by a metallic pin. The pin will act as internal chill to drag temperature from molten plastic and no shrink cavities will appear at this place. Estimation of temperature available at junction and 
amount of temperature dragged by metal insert can be scope of further research.

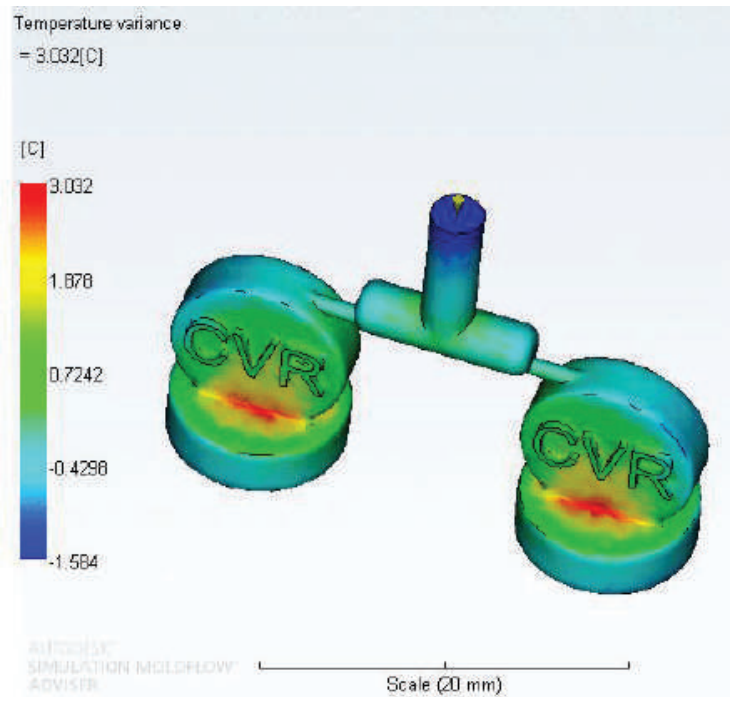

Figure 10. Temperature Variance Result

Low temperature at junction could have been a problem because the pin may cause temperature drop of flow front resulting cold shut or improper filling of mold cavity.

\section{E. Observation And Remeady of Air Trap}

Minute amount of air trap is observable in air traps result, the same is shown in Figure 11. The amount of trapped air is not excess. But trapping at mold wall interface can cause unfilled section and bad appearance of the product.

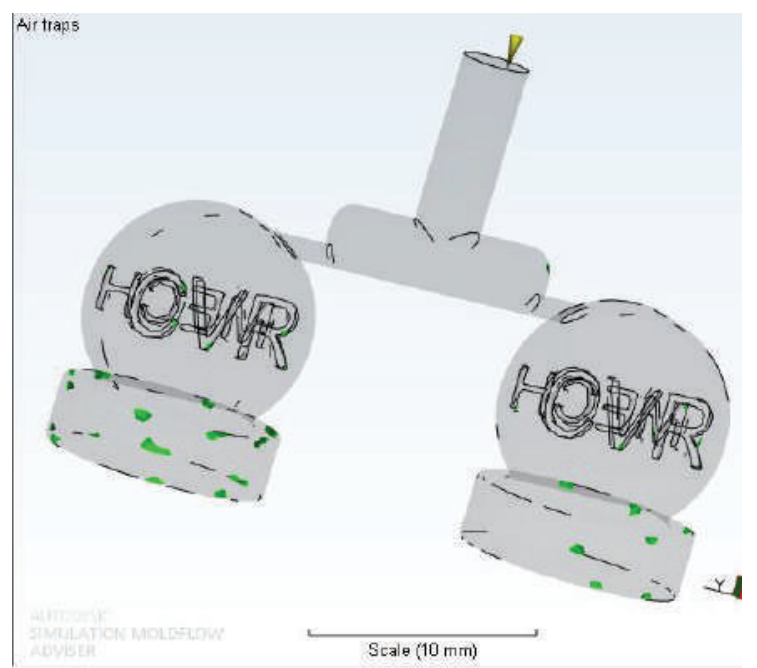

Figure 11. Air Entrapment Result

Air entrapment clearly indicates need of vents. As it is discussed that in the die there will be provision of placement of metallic insert prior to molding, the same provision can easily act as air vent. It is explained with the help of Figure 12 and Figure 13.

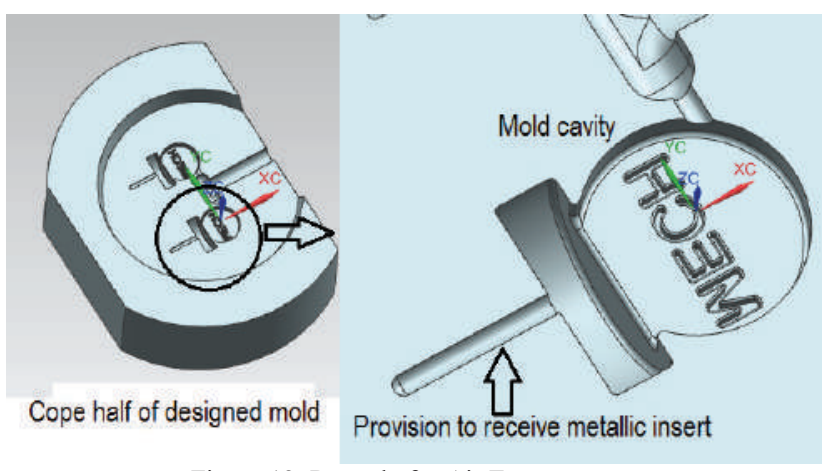

Figure 12. Remedy for Air Entrapment

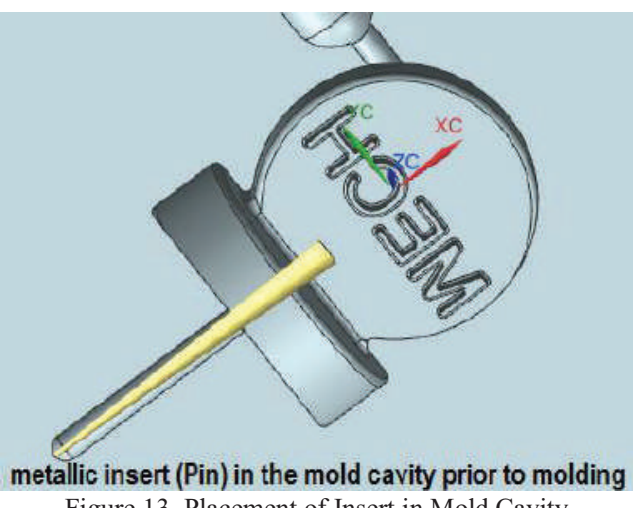

Figure 13. Placement of Insert in Mold Cavity

After placement of insert in the slot, the clearance at the insert- mold cavity interface is big enough to allow passage of trapped air and small enough to block the passage of molten material. In this small passage little amount of material may enter. But this very small volume of material will quickly lose its temperature to solidify, thereby preventing further flow of material through that passage.

Based on results obtained empirically and analyzed by simulation, the designed double cavity metal-plastic-insert injection molding die is shown in Figure 14 to Figure 16.

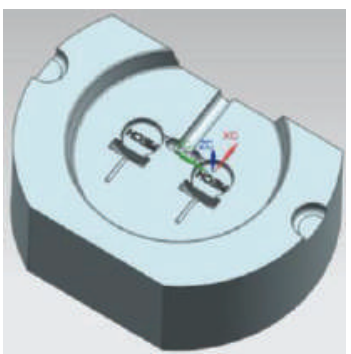

Figure 14. Cope Half of Designed Mold

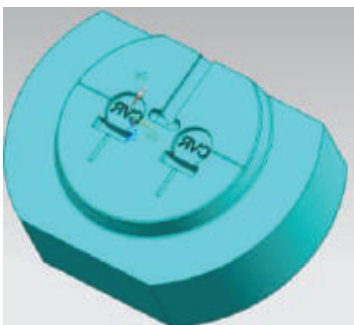

Figure 15. Drag Half of Designed Mold 


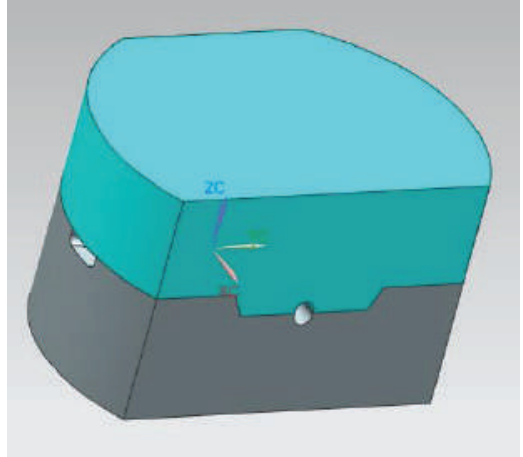

Figure 16. Die Assembly

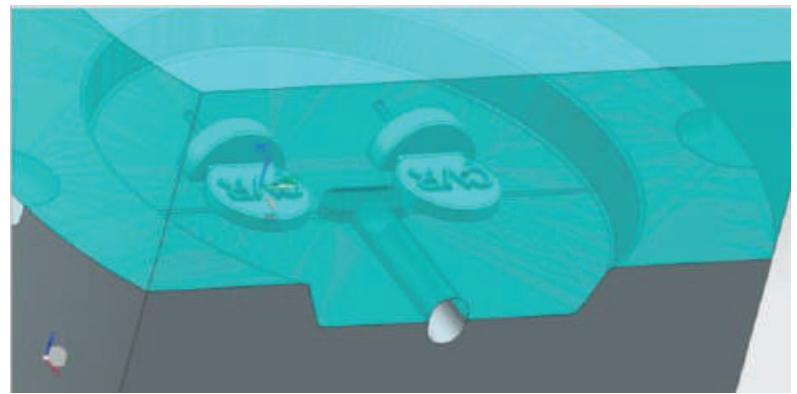

Figure 17. Visibility of Component in the Die

\section{F. Tool Material Selection}

It is well known that without proper mold material proper tooling cannot be achieved. A wide range of mould materials are used for fabrication of moulds and dies for plastics which include alloy steel, carbon steel, case hardened steel etc. Mold material selection will have to be carried out based on the requirements from product designer and mold maker [2].

\section{CONCLUSIONS}

High tooling cost and large required lead time are two major disadvantages of injection molding process. It is task of tool designer to overcome these drawbacks with his innovation and experience. Use of simple profiles may contribute to decrease in manufacturing time and cost. Complex profiles lead to high manufacturing and maintenance cost of tool. The tool discussed in this report can be designed for even higher number of cavities to produce more number of components in given amounts of time. But by increasing number of cavities, placement of inserts in mold cavity prior to molding can be a complex issue. This situation can be handled by using inserts with magnetic property.

Ultimately, it is the task of a designer to achieve profitability in design phase itself.

\section{REFERENCES}

[1] Kalpakjian S. and Steven R. Schmid, "Manufacturing Engineering and Technology". Pearsion Education, $4^{\text {th }}$ edition, pp. 564, 1995

[2] Technical committee, Technical Directory on Design and Tooling for Plastics, Central Institute of Plastic Engineering \& Technology. pp. 43-64, 1970.

[3] Engineers Tooling Service Input ETSI, Tool Engineering Parameters, Series 1, ISTE, pp. 24-34, 1970. 